\title{
Tensile behavior of bulk metallic glasses by in situ x-ray diffraction
}

\author{
X. D. Wang ${ }^{\text {a),b) }}$ \\ International Center for New-Structured Materials (ICNSM) and Laboratory of New-Structured Materials, \\ Department of Materials Science and Engineering, Zhejiang University, Hangzhou 310027, People's \\ Republic of China \\ J. Bednarcik, K. Saksl, and H. Franz ${ }^{a), c)}$ \\ HASYLAB am DESY, Notkestrasse 85, D-22603 Hamburg, Germany \\ Q. P. Cao and J. Z. Jiang ${ }^{a), d)}$ \\ International Center for New-Structured Materials (ICNSM) and Laboratory of New-Structured Materials, \\ Department of Materials Science and Engineering, Zhejiang University, Hangzhou 310027, People's \\ Republic of China
}

(Received 31 May 2007; accepted 31 July 2007; published online 23 August 2007)

\begin{abstract}
The authors report the use of in situ high-energy x-ray diffraction to detect the tensile behavior of two $\mathrm{Zr}$ - and La-based bulk metallic glasses (BMGs). Based on the diffraction data, the tensile elastic modulus and Poisson's ratio can be accurately evaluated. No excess free volume appears in the fractured region. However, a drastic change in atomic-level strains is found in the La-based BMG along the tensile direction, while a tiny crystalline component is detected in the fracture region of Zr-based BMG, which may be the different factors leading to the catastrophic failure of them, respectively. (C) 2007 American Institute of Physics. [DOI: 10.1063/1.2773945]
\end{abstract}

With the increase of the critical size of bulk metallic glasses (BMGs), current research work has focused on their mechanical properties. ${ }^{1-4}$ Similar to traditional oxide glasses, brittleness is also a crucial drawback of BMGs for their wide-spread potential applications. Although some BMGs exhibit pronounced plasticity under uniaxial compression or bending conditions, they are generally destroyed with catastrophic failure upon tension at room temperature with slow strain rate. ${ }^{5-8}$ Usually, a BMG with plasticity forms highdensity shear bands during loading, which can accumulate plastic strain and alleviate local stress concentration. Up to date, there is no report on a BMG showing tensile plasticity at room temperature with slow strain rates.It has been proven that high-energy $\mathrm{x}$-ray scattering can be used to measure the elastic strain under compression ${ }^{9,10}$ and to detect the change in excess free volume upon heating ${ }^{11}$ or homogeneous plastic deformation $^{12}$ of BMGs. In this letter, we present the difference in tensile behaviors of two BMGs, Zr-based BMG with high fracture strength and La-based BMG with low fracture strength, by using in situ $\mathrm{x}$-ray diffraction. It is found that the elastic modulus, excess free volume, and the strain distribution on atomic level during tension can be calculated based on the diffraction data. The tensile behaviors of these two BMGs are carefully compared.

Prealloyed ingots of nominal compositions $\mathrm{Zr}_{62} \mathrm{Al}_{8} \mathrm{Ni}_{13} \mathrm{Cu}_{17}$ and $\mathrm{La}_{62} \mathrm{Al}_{14}\left(\mathrm{Cu}_{5 / 6} \mathrm{Ag}_{1 / 6}\right){ }_{14} \mathrm{Co}_{5} \mathrm{Ni}_{5}$ were prepared by arc melting under a Ti-gettered purified argon atmosphere. From ingots, sheet-shaped samples $1 \mathrm{~mm}$ thick, $10 \mathrm{~mm}$ wide, and $60 \mathrm{~mm}$ long were prepared by suction casting in a water-cooled copper mold. The sheets without any artifacts were selected to fabricate tensile test specimens $\left(40 \times 10 \times 1 \mathrm{~mm}^{3}\right)$ with a $4 \mathrm{~mm}$ diameter reamed hole at each side. The gauge dimension for the sample is of about

\footnotetext{
a) Authors to whom correspondence should be addressed.

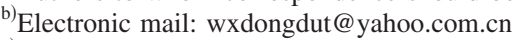

${ }^{c}$ Electronic mail: hermann.franz@desy.de

d)Electronic mail: jiangjz@zju.edu.cn
}

$12 \times 2 \times 1 \mathrm{~mm}^{3}$. On an operating platform a tensile/ compression module by Kammrath and Weiss $\mathrm{GmbH}$ (maximum loading $5000 \mathrm{~N}$ ) was placed, in which a fine-polished sample was fixed. The in situ structural measurement was conducted by using synchrotron x-ray diffraction at the BW5 station of HASYLAB, Hamburg. ${ }^{13}$ The beam size was 1 $\times 1 \mathrm{~mm}^{2}$ and the wavelength used was $0.12398 \AA$. Due to the limited width of the window between two sample holders, seven points ( $1 \mathrm{~mm}$ step) in the middle of each sample were available for scanning sequentially when holding a force each time. Diffraction patterns were recorded on an image plate (MAR 345, with $150 \times 150 \mu \mathrm{m}^{2}$ pixel size). The scattering intensity $I(q)$ versus scattering vector of the loading and the transverse directions were extracted by azimuthally caking $5^{\circ}$ fractions centered on each direction from the ring pattern and then integrating within these areas by using the software package FIT2D. ${ }^{14}$ From $I(q)$, the structure factor $S(q)\left(q<16 \AA^{-1}\right)$ and the pair distribution function (PDF) $G(r)$ could be obtained by PDFGETX2. ${ }^{15}$

When a material is subjected to an external tension, the atoms would move apart along the loading direction and close in the transverse. These movements are reflected by the change of positions of the first maximum in $I(q)$ or $S(q) .{ }^{10,11}$ Figure 1 displays in situ $I(q)$ curves of the tensile direction for $\mathrm{Zr}_{62} \mathrm{Al}_{8} \mathrm{Ni}_{13} \mathrm{Cu}_{17} \mathrm{BMG}$ with increasing tensile stress. The inset is the local magnification of the top part of the first peaks, showing that the peak positions change with stress in the tensile and transverse directions. the figure does not show the same curves for $\mathrm{La}_{62} \mathrm{Al}_{14}\left(\mathrm{Cu}_{5 / 6} \mathrm{Ag}_{1 / 6}\right)_{14} \mathrm{Co}_{5} \mathrm{Ni}_{5} \mathrm{BMG}$. It is clear that the increasing tensile stress causes the peaks in $I(q)$ to move to smaller $q$ values in the loading direction and while to higher $q$ values in the transverse, indicating the enlargement of distance between atoms in the loading direction and contraction in the transverse simultaneously. The shift of peak position in $I(q)$ of $\mathrm{Zr}_{62} \mathrm{Al}_{8} \mathrm{Ni}_{13} \mathrm{Cu}_{17}$ BMG upon tensile stress is nearly in a linear way. Due to finer stress steps, it shows that the peak position slightly deviates from 


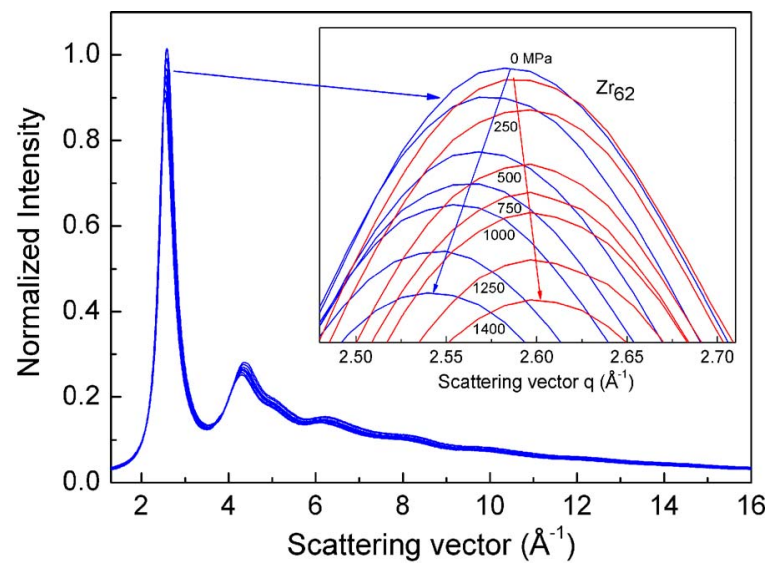

FIG. 1. (Color online) Normalized diffraction curves $I(q)$ of the tensile direction and the top part magnification of first peaks in $I(q)$ of tensile/ transverse directions changing with increasing stress for $\mathrm{Zr}_{62} \mathrm{Al}_{8} \mathrm{Ni}_{13} \mathrm{Cu}_{17}$ BMG.

the linear for $\mathrm{La}_{62} \mathrm{Al}_{14}\left(\mathrm{Cu}_{5 / 6} \mathrm{Ag}_{1 / 6}\right){ }_{14} \mathrm{Co}_{5} \mathrm{Ni}_{5}$ BMG at low stress stage. The difference between $q_{0}$ and $q$ [the first-peak positions in $I(q)$ under zero stress and stress $\sigma]$ reflects a rapid increase of stain with low stress in this alloy. The $q$ value in peak position was calibrated by using PEAKFIT software with AutoFit Peaks I Residuals option to identify the local maximum. ${ }^{16}$ Using Eq. (1), ${ }^{10}$ the elastic strains of these two BMGs can be evaluated.

$$
\varepsilon=\frac{d-d_{0}}{d_{0}}=\frac{q_{0}-q}{q},
$$

where $\varepsilon$ is the elastic strain; $d_{0}$ and $d$ denote the peak position in $G(r)$ (positions in real space) under zero stress and stress $\sigma$. Figure 2 shows the relationship between the tensile stress and the corresponding strain calculated by Eq. (1). By linearly fitting the points and calculating the ratio of strains between the transverse and tensile directions for each alloy, the tensile elastic modulus and Poisson' ratio can be obtained, to be about $83 \mathrm{GPa}$ and 0.37 for $\mathrm{Zr}_{62} \mathrm{Al}_{8} \mathrm{Ni}_{13} \mathrm{Cu}_{17} \quad \mathrm{BMG}$ and $34 \mathrm{GPa}$ and 0.36 for $\mathrm{La}_{62} \mathrm{Al}_{14}\left(\mathrm{Cu}_{5 / 6} \mathrm{Ag}_{1 / 6}\right){ }_{14} \mathrm{Co}_{5} \mathrm{Ni}_{5} \mathrm{BMG}$, respectively. The tensile stress-strain curves of these two BMGs at room temperature with a strain rate of $1 \times 10^{-4} \mathrm{~s}^{-1}$ are also illustrated in

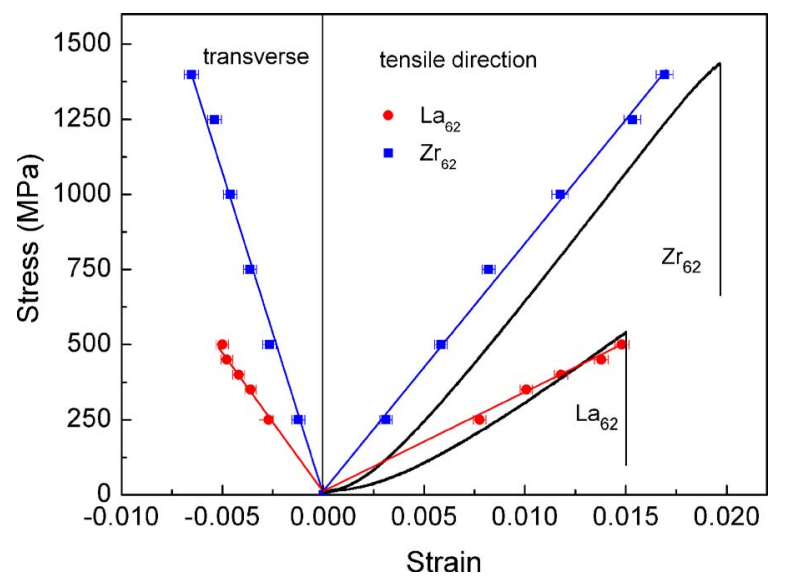

FIG. 2. (Color online) Strains determined from the diffraction data of tensile/transverse directions. In addition, the tensile stress-strain curves of $\mathrm{Zr}_{62} \mathrm{Al}_{8} \mathrm{Ni}_{13} \mathrm{Cu}_{17}$ and $\mathrm{La}_{62} \mathrm{Al}_{14}\left(\mathrm{Cu}_{5 / 6} \mathrm{Ag}_{1 / 6}\right) \mathrm{Co}_{5} \mathrm{Ni}_{5}$ BMGs are also included

transverse directions for each alloy. As shown in Fig. 3(b)
$\begin{aligned} & \text { for comparison. } \\ & \text { Downloaded } 24 \text { Aug } 2007 \text { to 131.169.38.107. Redistribution subject to AlP license or copyright, see http://apl.aip.org/apl/copyright.jsp }\end{aligned}$
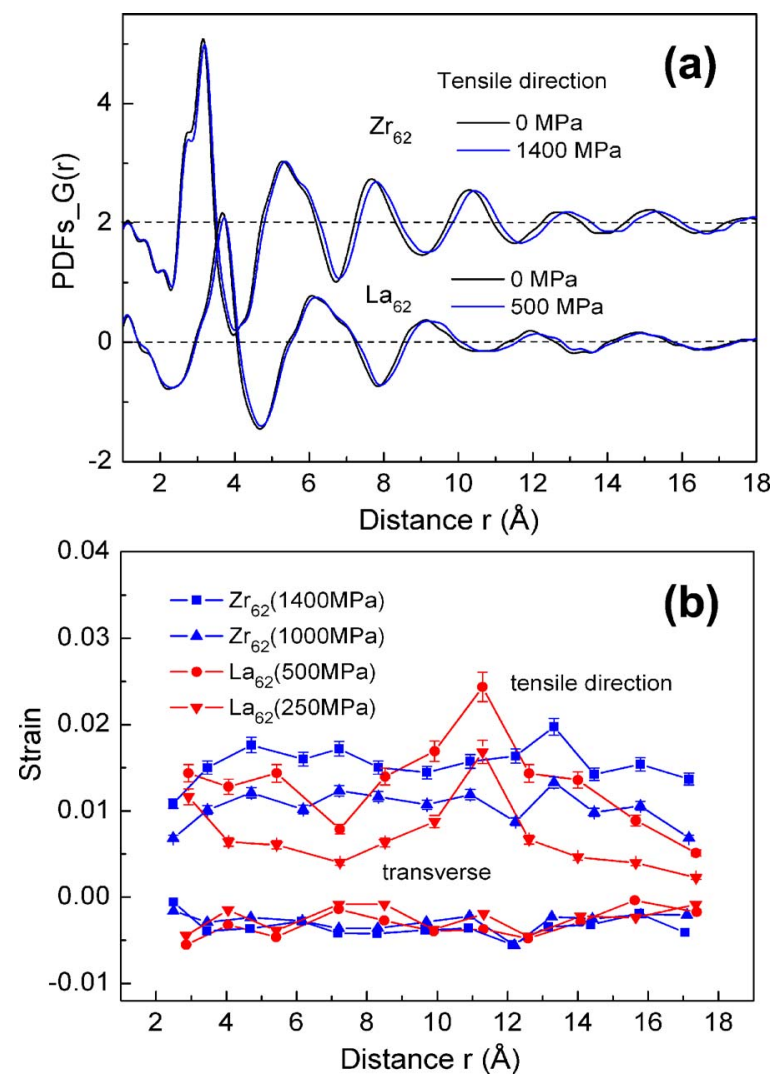

FIG. 3. (Color online) (a) Pair distribution functions $G(r)$ of as-cast and tensioned samples for both BMGs and (b) the atomic level strains determined from $G(r)$ of tensile/transverse directions under two different stress values.

Fig. 2. From these curves, one can see that both of them basically exhibit catastrophic failure upon tension, and $\mathrm{Zr}_{62} \mathrm{Al}_{8} \mathrm{Ni}_{13} \mathrm{Cu}_{17}$ shows a sign of yielding prior to tensile fracture even though the compressive plasticity of this alloy is more than $10 \%{ }^{17}$ The elastic modulus, tensile fracture strength, and elastic limit are $81 \mathrm{GPa}, 1460 \mathrm{MPa}$, and $1.9 \%$, respectively, for $\mathrm{Zr}_{62} \mathrm{Al}_{8} \mathrm{Ni}_{13} \mathrm{Cu}_{17}$ BMG, and $38 \mathrm{GPa}, 540 \mathrm{MPa}$, and $1.5 \%$, respectively, for $\mathrm{La}_{62} \mathrm{Al}_{14}\left(\mathrm{Cu}_{5 / 6} \mathrm{Ag}_{1 / 6}\right){ }_{14} \mathrm{Co}_{5} \mathrm{Ni}_{5} \mathrm{BMG}$, in agreement with the data obtained from x-ray diffraction (XRD) measurements in Fig. 2. The existing displacement in strains is likely due to some error in zero strain determination or the base line of the tensile machine. In addition, the data of Young's modulus and Poisson's ratio were also measured by using a MATEC 6600 model ultrasonic system with the sensitivity of $0.5 \mathrm{~ns}$ to be $80 \mathrm{GPa}$ and 0.38 for $\mathrm{Zr}_{62} \mathrm{Al}_{8} \mathrm{Ni}_{13} \mathrm{Cu}_{17}$ BMG and $35 \mathrm{GPa}$ and 0.36 for $\mathrm{La}_{62} \mathrm{Al}_{14}\left(\mathrm{Cu}_{5 / 6} \mathrm{Ag}_{1 / 6}\right){ }_{14} \mathrm{Co}_{5} \mathrm{Ni}_{5}$ BMG. All this confirms that the XRD technique is suitable to study tension behavior of bulk metallic glasses.

The pair distribution functions $G(r)$ of each sample upon the stress adjacent to fracture strength were obtained by Fourier transformation of the $S(q)$ data, reflecting a statistical average in the number of surrounding atoms $(r=18 \AA)$, including increase or decease around each central atom. From the shift of peak position in $G(r)$, the strain in atomic level can be estimated. To get rid of the uncertainty of peak position in $G(r)$, as shown in Fig. 3(a), that sometimes shows peak splitting or asymmetry, the points with $G(r)=0$ were measured to determine the strain change in the tensile/ transverse directions for each alloy. As shown in Fig. 3(b) AIP license or copyright, see http://apl.aip.org/apl/copyright.jsp 


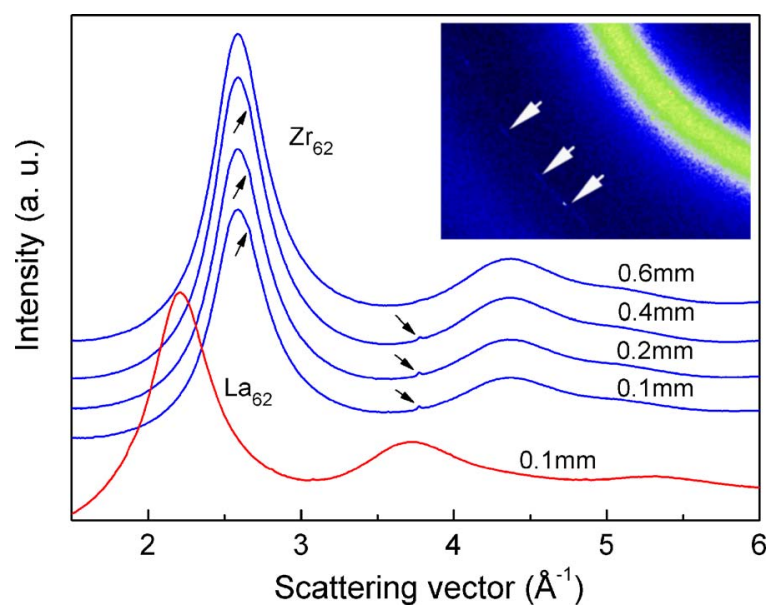

FIG. 4. (Color online) High-resolution $I(q)$ curves obtained for the fractured samples by using $0.1 \mathrm{~mm}$ sized beam at different depths below the fracture surface. The inset shows the part of Bragg ring on a two-dimensional XRD pattern, correspondingly.

larger strain fluctuation in the range of $5 \sim 12 \AA$ along tensile direction is detected for $\mathrm{La}_{62} \mathrm{Al}_{14}\left(\mathrm{Cu}_{5 / 6} \mathrm{Ag}_{1 / 6}\right){ }_{14} \mathrm{Co}_{5} \mathrm{Ni}_{5} \mathrm{BMG}$, whereas the stain variation becomes rather small for $\mathrm{Zr}_{62} \mathrm{Al}_{8} \mathrm{Ni}_{13} \mathrm{Cu}_{17} \mathrm{BMG}$. The local strains are even beyond the elastic limit of $\mathrm{La}_{62} \mathrm{Al}_{14}\left(\mathrm{Cu}_{5 / 6} \mathrm{Ag}_{1 / 6}\right){ }_{14} \mathrm{Co}_{5} \mathrm{Ni}_{5} \mathrm{BMG}$ at the place where $r=11 \AA$ though it is still under the elastic deformation. In contrast, the strain changes along the transverse direction for both BMGs are quite similar and no drastic variation is detected. It seems that the larger variation in local strain could cause La-based BMG to be catastrophic failure easily with relative low elastic limit. Different distributions in local stains were also observed in $\mathrm{Zr}_{57} \mathrm{Ti}_{5} \mathrm{Cu}_{20} \mathrm{Ni}_{8} \mathrm{Al}_{10}$ with high fracture strength, ${ }^{10}$ and rather tremendous in $\mathrm{Mg}-\mathrm{Cu}-\mathrm{Y}$ BMG with low fracture strength. ${ }^{9}$ At the moment, the origin for this inhomogeneous variation in local strain is not clear yet and more studies are needed.

The fracture of $\mathrm{Zr}_{62} \mathrm{Al}_{8} \mathrm{Ni}_{13} \mathrm{Cu}_{5}$ BMG almost follows the Mohr-Coulomb criterion ${ }^{5}$ with the fracture angle of nearly $55^{\circ}$ to the tensile direction, while $\mathrm{La}_{62} \mathrm{Al}_{14}\left(\mathrm{Cu}_{5 / 6} \mathrm{Ag}_{1 / 6}\right)_{14} \mathrm{Co}_{5} \mathrm{Ni}_{5}$ BMG abides by the maximum normal stress criterion, being fractured perpendicular to the tensile direction. The fracture of BMGs upon compression is often ascribed to the formation and coalescence of excess free volume. ${ }^{18}$ However, it is quite difficult to measure the free volume content in BMGs by conventional experimental methods. In this work the region within $5 \mathrm{~mm}$ width from the fractured surface was examined by high-resolution XRD with the beam size of $0.1 \times 2 \mathrm{~mm}^{2}$ and wavelength of $0.110696 \AA$ at the beamline PETRA2 of HASYLAB. It is confirmed that they are almost the same, e.g., the first peak position at $2.585(1) \AA^{-1}$ for the as-cast $\mathrm{Zr}_{62} \mathrm{Al}_{8} \mathrm{Ni}_{13} \mathrm{Cu}_{17}$ BMG and 2.585(2) $\AA^{-1}$ for the fractured one, indicating that no obvious increase of excess free volume appears in the fractured region. However, on XRD patterns, Bragg diffraction from crystalline component is clearly observed in the fracture region of about $0.5 \mathrm{~mm}$ width for $\mathrm{Zr}_{62} \mathrm{Al}_{8} \mathrm{Ni}_{13} \mathrm{Cu}_{17}$ $\mathrm{BMG}$, as shown in Fig. 4. Beyond this range, only amorphous phase is detected, indicating that the crystalline phase with a small fraction is likely formed upon tension rather than pre-existing during casting. However, no crystalline phase is detected for $\mathrm{La}_{62} \mathrm{Al}_{14}\left(\mathrm{Cu}_{5 / 6} \mathrm{Ag}_{1 / 6}\right)_{14} \mathrm{Co}_{5} \mathrm{Ni}_{5} \mathrm{BMG}$ even in the region of only $0.1 \mathrm{~mm}$ adjacent to the fracture surface. Comparing with uniaxial compression, no crystalline phase was detected in a $55 \%$ strained $\mathrm{Zr}_{62} \mathrm{Al}_{8} \mathrm{Ni}_{13} \mathrm{Cu}_{17}$ sample. ${ }^{17}$ This suggests that the existing tiny crystalline component could destroy the homogeneity of this BMG and promote the catastrophic failure.

In summary, no tensile plasticity is observed in $\mathrm{Zr}_{62} \mathrm{Al}_{8} \mathrm{Ni}_{13} \mathrm{Cu}_{17}$ and $\mathrm{La}_{62} \mathrm{Al}_{14}\left(\mathrm{Cu}_{5 / 6} \mathrm{Ag}_{1 / 6}\right)_{14} \mathrm{Co}_{5} \mathrm{Ni}_{5}$ BMGs though the $\mathrm{Zr}_{62} \mathrm{Al}_{8} \mathrm{Ni}_{13} \mathrm{Cu}_{17} \mathrm{BMG}$ exhibits a sign of yielding before catastrophic failure. Using the diffraction data by in situ high-energy $\mathrm{x}$-ray diffraction, the tensile modulus and Poisson's ratio can be accurately evaluated. Also no excess free volume is found in the fractured regions. However, for $\mathrm{La}_{62} \mathrm{Al}_{14}\left(\mathrm{Cu}_{5 / 6} \mathrm{Ag}_{1 / 6}\right) \mathrm{Co}_{5} \mathrm{Ni}_{5}$ BMG a large variation in atomic-level strains was detected along the tensile direction and no crystalline precipitates are observed after failure. Interestingly, the situation is just opposite for $\mathrm{Zr}_{62} \mathrm{Al}_{8} \mathrm{Ni}_{13} \mathrm{Cu}_{17}$ $\mathrm{BMG}$, in which local strains slightly varied along both tensile and transverse directions and a tiny crystalline component was detected at the fractured region of about $0.5 \mathrm{~mm}$ layer.

The authors would like to thank the HASYLAB staff at DESY, Germany, for the assistance during the measurements at BW5. Financial support from the National Natural Science Foundation of China (Grant Nos. 50341032, 50425102, and 50601021), the Ministry of Science and Technology of China (Grant Nos. 2004/249/37-14 and 2004/250/31-01A), the Ministry of Education of China (Grant Nos. 2.005E + 10 and 2005-55), Zhejiang University-Helmholtz cooperation fund, and Zhejiang University is gratefully acknowledged.

${ }^{1}$ H. A. Bruck, T. Christman, A. J. Rosakis, and W. L. Johnson, Scr. Metall. Mater. 30, 429 (1994).

${ }^{2}$ C. C. Hays, C. P. Kim, and W. L. Johnson, Phys. Rev. Lett. 84, 2901 (2000).

${ }^{3}$ J. Das, M. B. Tang, K. B. Kim, R. Theissmann, F. Baier, W. H. Wang, and J. Eckert, Phys. Rev. Lett. 94, 205501 (2005).

${ }^{4}$ S.-W. Lee, M.-Y. Huh, E. Fleury, and J.-C. Lee, Acta Mater. 54, 349 (2006); C. A. Schuh, T. C. Hufnagel, and U. Ramamurty, ibid. 55, 4067 (2007).

5 Z. F. Zhang, J. Eckert, and L. Schultz, Acta Mater. 51, 1167 (2003).

${ }^{6}$ A. V. Sergueeva, N. A. Mara, J. D. Kuntz, E. J. Lavernia, and A. K. Mukherjee, Philos. Mag. 85, 2671 (2005).

${ }^{7}$ C. A. Schuh and A. C. Lund, Nat. Mater. 2, 449 (2003).

${ }^{8}$ Z. F. Zhang, G. He, J. Eckert, and L. Schultz, Phys. Rev. Lett. 91, 045505 (2003).

${ }^{9}$ H. F. Poulsen, J. A. Wert, J. Neuefeind, V. Honkimaki, and M. Daymond, Nat. Mater. 4, 33 (2005).

${ }^{10}$ T. C. Hufnagel, R. T. Ott, and J. Almer, Phys. Rev. B 73, 064204 (2006).

${ }^{11}$ A. R. Yavari, A. L. Moulec, A. Inoue, N. Nishiyama, N. Lupu, E. Matsubara, W. J. Botta, G. Vaughan, M. D. Michiel, and A. Kvick, Acta Mater. 53, 1611 (2005).

${ }^{12}$ R. T. Ott, M. J. Kramer, M. F. Besser, and D. J. Sordelet, Acta Mater. 54, 2463 (2006).

${ }^{13}$ R. Bouchard, D. Hupfeld, T. Lippmann, J. Neuefeind, H.-B. Neumann, H. F. Poulsen, U. Rütt, T. Schmidt, J. R. Schneider, J. Süssenbach, and M. von Zimmermann, Synchrotron Radiat. 5, 90 (1998).

${ }^{14}$ A. P. Hammersley, S. O. Svensson, M. Hanfland, A. N. Fitch, and D. Häusermann, High Press. Res. 14, 235 (1996); http://www.esrf.eu/ computing/scientific/FIT2D/

${ }^{15}$ I.-K. Jeong, J. Thompson, A. M. P. Turner, and S. J. L. Billinge, J. Appl. Crystallogr. 34, 536 (2001); http://www.pa.msu.edu/cmp/billinge-group/ programs/PDFgetX2/

${ }^{16} \mathrm{http}: / /$ www.aspiresoftwareintl.com/html/peakfit.html

${ }^{17}$ X. D. Wang, L. Yang, J. Z. Jiang, K. Saksl, H. Franz, H.-J. Fecht, Y. G. Liu, and H. S. Xie, J. Mater. Res. (to be published).

${ }^{18}$ W. J. Wright, T. C. Hufnagel, and W. D. Nix, J. Appl. Phys. 93, 1432 (2003). 